\title{
Implementation of a decision aid for recognition and correction of volume alterations $\left(\operatorname{Recova}^{\circledR}\right)$ in haemodialysis patients
}

\author{
Jenny Stenberg ${ }^{a}$ (D) Magnus Lindberg ${ }^{b, c}$ (D) and Hans Furuland ${ }^{a}$

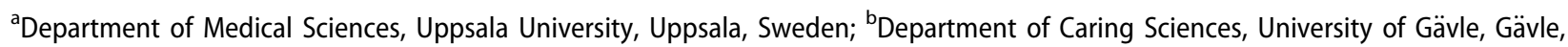 \\ Sweden; 'Department of Public Health and Caring Sciences, Uppsala University, Uppsala, Sweden
}

\begin{abstract}
Background: Fluid overload is associated with mortality in haemodialysis patients, and $30 \%$ of patients remain fluid-overloaded after dialysis. The aim of this study was to evaluate if implementation of Recova ${ }^{\circledR}$, a decision aid combining clinical assessment with bioimpedance spectroscopy, facilitates individualization of target weight determination and thereby contributes to improved fluid status in maintenance haemodialysis patients.

Methods: The impact of the implementation was measured as the proportion of participants at an adequate target weight at the end of the study, assessed as change in symptoms, hydration status, and N-terminal pro-brain natriuretic peptide (NT-proBNP). Nurses were instructed to use Recova every 2 weeks, and the process of the intervention was measured as frequencies of fluid status assessments, bioimpedance measurements, and target weight adjustments.

Results: Forty-nine patients at two haemodialysis units were enrolled. In participants with fluid overload $(n=10)$, both overhydration and fluid overload symptom score decreased. In fluid-depleted participants $(n=20)$, target weight adjustment frequency and the estimated target weight increased. The post-dialytic negative overhydration was reduced, but NT-proBNP increased.

Conclusions: Implementation of Recova in haemodialysis care increased the monthly frequencies of bioimpedance measurements and target weight adjustments, and it contributed to symptom reduction.

Trial registration: The Uppsala County Council Registry of Clinical Trials: FoU 2019-0001-15.
\end{abstract}

\section{ARTICLE HISTORY}

Received 13 May 2020

Revised 27 July 2020

Accepted 29 July 2020

\section{KEYWORDS}

Body composition; body fluids; decision support techniques; electric impedance; prospective studies; renal dialysis; water-electrolyte imbalance

\section{Introduction}

Haemodialysis is lifesaving, and its purpose is to replace the vital functions of the failing kidneys. It has two primary goals: to remove uraemic toxins and to restore sodium and water homeostasis (1). The use of an estimated ideal body weight, usually referred to as the dry weight or target weight, remains the standard of care for volume management (2), but there is no consensus on its absolute definition, and even small changes in target weight may be clinically important. Clinical examinations are insensitive to subtle volume alterations, and insufficiently prevent treatment-related complications (3).

In recent years, bioimpedance spectroscopy has gained popularity for assessing body composition and fluid status, due to its simplicity and low cost $(3,4)$. The body composition model describes the intra- and extracellular water (ICW, ECW) content of lean and adipose tissue, and excess fluid, expressed as overhydration $(\mathrm{OH})$ in litres (5). Results from randomized trials evaluating the effect of bioimpedanceguided fluid management are promising; the method can improve blood pressure control, hydration status, and arterial stiffness measurements $(6,7)$. However, there are difficulties associated with reduction of excessive fluid volume, including intradialytic hypotension, ischaemia of heart, brain, and gut, loss of residual renal function, and vascular access thrombosis $(8,9)$. It has been emphasized that bioimpedance cannot provide a simple target applicable to all patients $(4,10,11)$, and how it is actually used to guide the complex intervention of setting a desirable target weight has been difficult to capture $(12,13)$.

Fluid management requires a multidisciplinary effort and a combination of clinically and technically derived parameters. At units where nurses are authorized to change target weight, target weights are adjusted more often, and systolic blood pressure pre-dialysis is significantly lower (14). Also, having a protocol specifying how often to assess target weight in most patients is associated with lower all-cause mortality (15). Nevertheless, most haemodialysis units have not agreed on a fluid management policy $(14,16)$.

A decision aid, Recova ${ }^{\circledR}$, which standardizes the process of recording, scoring, and responding to changes in routinely measured physiological parameters and incorporates bioimpedance in target weight determination, has been 
developed. The purpose of Recova is to allow early recognition and adequate response to fluid status alterations in haemodialysis patients (17).

The aim of this study was to evaluate if implementation of Recova facilitates individualization of target weight determination and thereby contributes to improved fluid status in maintenance haemodialysis patients.

\section{Materials and methods}

This prospective implementation study was designed as a non-randomized, single-blinded label intervention, carried out at two haemodialysis units within one centre. Patients with end-stage renal disease, undergoing maintenance haemodialysis 2-5 times a week, were screened for enrolment. Criteria for inclusion were haemodialysis treatment $\geq 3$ months, age $\geq 18$ years, and ability to understand and speak Swedish. The exclusion criterion was residual renal function large enough that ultrafiltration was not needed.

Based on the participants' predominant symptoms and on bioimpedance-measured hydration status, four fluid status groups were defined prior to the intervention: $A$, symptoms of fluid overload but negative $\mathrm{OH}$; $\mathrm{B}$, symptoms of fluid overload and positive $\mathrm{OH} ; \mathrm{C}$, symptoms of fluid depletion (or absence of symptoms) but positive $\mathrm{OH} ; \mathrm{D}$, symptoms of fluid depletion (or absence of symptoms) and negative $\mathrm{OH}$. The categorization of study participants and the estimated urgency of need for correction of target weight were not presented to the staff of the clinics.

\section{Intervention}

The three parts of the Recova tool, which has been thoroughly described by Stenberg et al. (17), were presented to the haemodialysis units' nurses through workshop sessions:

1. A symptom-scoring system systematizing physiological parameters already used in clinical assessment of fluid status (Figure 1).

2. Thresholds and triggers for action indicating any need for action, based on the participant's total symptom score (Appendix A).

3. A decision aid algorithm, which combines clinical assessment with bioimpedance, and suggests a clinical response and individualized target for $\mathrm{OH}$ post-dialysis (OH post) (Appendix B).

The nurses were instructed to use Recova to systematically assess the study participants' fluid status and to score their symptoms of fluid overload/depletion every 14 days. They were also instructed to respond to the Recova threshold values as appropriate, to perform bioimpedance measurements if necessary, and to alert the nurse or clinician responsible, as recommended in the tool. If appropriate, they

\section{Symptom Score}

\begin{tabular}{|c|c|c|c|c|c|c|c|}
\hline & \multicolumn{3}{|c|}{ Symptoms of fluid depletion (0-8 points) } & \multirow[b]{2}{*}{0} & \multicolumn{3}{|c|}{ Symptoms of fluid overload (0-8 points) } \\
\hline & 3 & 2 & 1 & & 1 & 2 & 3 \\
\hline Dyspnea at rest & & & & \multirow{7}{*}{ 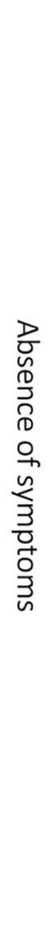 } & Recumbent & Two cushions & Sitting \\
\hline Pretibial edema & & & & & Weak & Severe & \\
\hline $\begin{array}{l}\text { Symptoms of } \\
\text { FO between HD } \\
\text { sessions }\end{array}$ & & & & & $\begin{array}{l}\text { Unexpectedly } \\
\text { low weight gain }\end{array}$ & $\begin{array}{l}\text { Chronic } \\
\text { coughing } \\
\text { (new) }\end{array}$ & \\
\hline $\begin{array}{l}\text { Blood pressure } \\
\text { increase }\end{array}$ & & & & & $\begin{array}{l}\text { BP increase } \\
\text { after UF }\end{array}$ & & \\
\hline $\begin{array}{l}\text { Muscle cramps } \\
\text { (calf) }\end{array}$ & & Severe & Moderate & & & & \\
\hline $\begin{array}{l}\text { Symptomatic } \\
\text { IDH and } \geq 20 \\
\mathrm{mmHg} \text { sBP } \\
\text { decrease }\end{array}$ & $\begin{array}{l}\text { Vomiting or } \\
\text { unconscious- } \\
\text { ness }\end{array}$ & $\begin{array}{l}\text { Requiring } \\
\text { saline } \\
\text { infusion or } \\
\text { stopped UF }\end{array}$ & $\begin{array}{l}\text { Requiring } \\
\text { position } \\
\text { change }\end{array}$ & & & & \\
\hline $\begin{array}{l}\text { Symptoms of FD } \\
\text { between HD } \\
\text { sessions }\end{array}$ & $\begin{array}{l}\text { Dizziness, } \\
\text { symptomatic } \\
\text { hypotension }\end{array}$ & $\begin{array}{l}\text { Limpness } \\
\text { /tiredness }\end{array}$ & $\begin{array}{l}\text { Thirst directly } \\
\text { after HD }\end{array}$ & & & & \\
\hline
\end{tabular}

FO: fluid overload; HD: hemodialysis; IDH: intradialytic hypotension, sBP: systolic blood pressure; FD: fluid depletion

Figure 1. The Recova ${ }^{\circledR}$ scoring system for systemized clinical assessment of fluid status (from Reference [18]). The symptom score can total 0-16 points: $0-8$ fluid overload points and 0-8 fluid depletion points. 
Table 1. Fluid status groups, the suggested clinical response and the plausible post-dialysis target weight to aim for in each group - as defined by recova.

\begin{tabular}{|c|c|c|c|c|}
\hline & $A$ & B & $C$ & D \\
\hline $\begin{array}{l}\text { Clinically assessed fluid status } \\
\mathrm{OH} \text { post (BIS measured) }\end{array}$ & $\begin{array}{l}\text { Overload } \\
\leq 0 \mathrm{~L}\end{array}$ & $\begin{array}{l}\text { Overload } \\
>0 \mathrm{~L}\end{array}$ & $\begin{array}{l}\text { Depletion or no symptoms } \\
>0 \mathrm{~L}\end{array}$ & $\begin{array}{l}\text { Depletion or no symptoms } \\
\leq 0 \mathrm{~L}\end{array}$ \\
\hline $\begin{array}{l}\text { Suggested clinical response } \\
\text { Plausible } \mathrm{OH} \text { post target }\end{array}$ & $\begin{array}{l}\text { Decrease TW } 0.5-1 \mathrm{~kg} / \text { week } \\
-2 \text { to } 0 \mathrm{~L}\end{array}$ & $\begin{array}{l}\text { Decrease TW } 0.5-1 \mathrm{~kg} / \text { week } \\
\pm 1 \mathrm{~L}\end{array}$ & $\begin{array}{l}\text { First, treat malnutrition and inflammation } \\
0 \text { to }+2 \mathrm{~L}\end{array}$ & $\begin{array}{l}\text { Increase TW } 0.5-1 \mathrm{~kg} / \text { week } \\
\pm 1 \mathrm{~L}\end{array}$ \\
\hline
\end{tabular}

BIS: bioimpedance spectroscopy; $\mathrm{OH}$ : overhydration; TW: target weight.

were encouraged to initiate target weight adjustments. Target weight determination is the responsibility of the nephrologist, but nurses at most Swedish haemodialysis units are authorized to initiate target weight adjustments of 0.5-1 L (14).

A copy of the complete Recova tool (Figure 1, Appendices $A$ and $B$ ) and a protocol for recording assessments were included in the medical record of each study participant. At the morning meetings on the days scheduled for assessment (every 14 days), the nurses on duty were reminded to assess the study participants' fluid status. In the first haemodialysis unit, the intervention ran for 4 months, May-August 2019. In the second unit, the intervention ran for 3 months, September-November 2019.

\section{Study of the intervention}

The impact of the intervention was measured as proportion of study participants at an adequate target weight at the end of the study, assessed as change in symptoms and hydration status. Also change in $\mathrm{N}$-terminal pro-brain natriuretic peptide (NT-proBNP), a biomarker associated with overhydration in haemodialysis patients (18), was examined. The four fluid status groups, as defined by Recova, the suggested clinical response, and the plausible post-dialysis target weight to aim for in each group are presented in Table 1.

The process of the intervention was measured as frequency of fluid status assessments and change in frequencies of bioimpedance measurements and target weight adjustments, compared with 6 months prior to the intervention.

\section{Measures}

\section{Laboratory data}

Blood samples for analysis of NT-proBNP were collected at the beginning of the dialysis session, from the vascular access or from the arterial part of the tubing system, and sent to the hospital's certified laboratory. Analyses were performed in accordance with the laboratory's normal routines. Systolic and diastolic blood pressure, body weight, and ultrafiltration volume were recorded. Additional laboratory results, dialysis prescriptions, and retrospective data on frequencies of bioimpedance measurements and target weight adjustments were retrieved from medical records.

\section{Measure of hydration status}

Each participant's hydration status was assessed before a mid-week haemodialysis session, at baseline, and after either
3 or 4 months, using the Body Composition Monitor (BCM, Fresenius Medical Care, Bad Homburg, Germany). The BCM measures impedance at 50 frequencies and automatically determines total body water, ECW volume, ICW volume, and $\mathrm{OH}$ volume. It defines $\mathrm{OH}$ as the difference between the patient's expected ECW under normal physiological conditions and their actual ECW $(19,20)$. In healthy subjects, normal hydration ranges from -1.1 to $+1.1 \mathrm{~L} \mathrm{OH}(21)$. In this study hydration status was defined as either positive or negative $\mathrm{OH}$, depending on whether a participant's estimated $\mathrm{OH}$ post was $>0 \mathrm{~L}$ or $\leq 0 \mathrm{~L}$. $\mathrm{OH}$ post was estimated by subtracting planned ultrafiltration volume from $\mathrm{OH}$ as measured pre-dialysis.

\section{Assessment of fluid status}

At baseline, the Recova symptom scoring system was used to clinically assess and score each participant's fluid status (Figure 1). In order to categorize the participant's fluid status, depletion score was subtracted from overload score. Depending on whether the sum was positive or negative, fluid status was defined as either fluid overload or fluid depletion.

\section{Thresholds for action}

In order to measure the urgency of need for correction of the target weight, the total symptom score was calculated. According to Recova, if the total sum is 0 , no further action is required, but evaluation of the target weight should be performed every second week. If the score is $1-4$, the target weight should be questioned; if it is 5-6, the target weight should be adjusted; and if it is 7 or more, there is an immediate need for evaluation of hydration status and target weight adjustment (Appendix $A$ ).

\section{Statistical analysis}

Due to the low sample size, all data were considered nonparametric. Descriptive data are presented as median (Md) and inter-quartile range (IQR) or as percentage/frequency, as appropriate. Differences at baseline between the four groups were tested for significance with Kruskal-Wallis $H$ for independent groups of non-parametric variables. Within each group, differences between baseline and end-of-study were tested for significance with Wilcoxon's non-parametric test for dependent groups. Correlations between measures of hydration status and intervention-driven response were analysed with Spearman's rank correlation or chi-square tests, as appropriate. Statistical significance was inferred at $P \leq 0.05$. Statistical analyses were performed using GNU PSPP version 1.2.0, software for statistical analysis (Free Software 
Foundation, Inc., Boston, MA, USA). For reporting, the SQUIRE guidelines (22), a framework for reporting new knowledge on how to improve health care, were used.

\section{Ethical considerations}

The study complied with the declaration of Helsinki, and all enrolled study participants provided written informed consent. Ethical approval was obtained from the Swedish Ethical Review Authority, Dnr 2019-00011, before the study commenced.

\section{Trial registration details}

The trial was registered in the Uppsala County Council Registry of Clinical Trials (Kansliet för kliniska prövningar); trial registration number: FoU 2019-0001-15, Uppsala, Sweden 2019-02-08. Details available upon request (kliniskaprovningar@akademiska.se).

\section{Results}

\section{Study cohort characteristics}

Forty-nine haemodialysis patients, including 32 males (65\%), with a mean age of $73(67-80)$ years, were enrolled in the study. The median $\mathrm{OH}$ pre-dialysis $(\mathrm{OH}$ pre) in the sample was $1.7(0.9-3.4) \mathrm{L}, \mathrm{OH}$ post was $0.10(-0.80$ to 1.3$) \mathrm{L}$, and NT-proBNP was $9270(2490-19,600) \mathrm{ng} / \mathrm{L}$. Except for $\mathrm{OH}$, fluid overload score, and NT-proBNP, there were no statistical differences in characteristics between the four fluid status groups (Table 2). However, the participants were not evenly distributed in the four groups, and in the largest groups, $C$ and $D$, a large number of participants reported no symptoms of either fluid overload or fluid depletion (Figure 3).

At baseline, nine individuals (18.3\%) had a clinically assessed volume status score of $\geq 5$, indicating an urgent need for target weight adjustment, and about 50\% had a volume status score of 1-4. One-third of the participants had no symptoms of either fluid overload or fluid depletion. Table 3 shows the main characteristics of the whole study cohort.

\section{Intervention evolution over time}

Prior to the intervention, bioimpedance measurements were performed 0.5 times/patient/month, and there was no significant difference in target weight adjustment frequency between the two haemodialysis units. In the first unit, the staff were given the full responsibility to follow the protocol without further support. However, only $67 \%$ of the expected assessments were performed. Therefore, in the second unit, the first author visited the dialysis unit every second week to check if the intervention was carried out as intended and to support the nurses in their response to recognized fluid alterations. Hence, in the second haemodialysis unit, $100 \%$ of the expected assessments were performed.

\section{Process measures}

The monthly frequencies of both performed bioimpedance measurements and target weight adjustments increased by 1.5 in the first unit. In the second unit, there was a twofold increase in bioimpedance measurement frequency and a close to twofold increase in target weight adjustment frequency (Table 4). There was a correlation between frequency of bioimpedance measurements and frequency of target weight adjustments. Fluid overload symptoms correlated with $\mathrm{OH}$ post and NT-proBNP (Table 5).

\section{Outcome measures}

Group A - symptoms of fluid overload but negative $\mathrm{OH}$ In group $\mathrm{A}(n=4), \mathrm{OH}$ post was $-1.55(-2.6$ to -0.35$) \mathrm{L}$ at baseline, despite symptoms of fluid overload (Figure 2). However, in contrast to suggested clinical response (Table 1), the prescribed target weight increased in three cases. Despite this, two participants were relieved from symptoms of fluid overload (Figure 3), and at the end of the study all participants had reached the Recova-defined target for group A, that is $\mathrm{OH}$ post below $0 \mathrm{~L}$. At baseline, NT-proBNP was $27,150(10,735-52,400) \mathrm{ng} / \mathrm{L}$. The levels decreased in three cases but increased in one, where the participant had a decrease in lean and adipose tissue. At the group level, there was no significant change in NT-proBNP (Table 6).

\section{Group B - symptoms of fluid overload and positive $\mathrm{OH}$}

At baseline, all participants in group $B(n=10)$ had symptoms of fluid overload, and $\mathrm{OH}$ post was $1.85(1.4-2.1) \mathrm{L}$. The target weights decreased in seven cases, were unchanged in two, and increased in one. At the end of the study, five individuals had reached the target for group $B$, that is $\mathrm{OH}$ post $\pm 1.1 \mathrm{~L}$. Three participants had remaining symptoms of fluid overload, one was relieved of symptoms, and five had symptoms of fluid depletion. At baseline, this group had the highest NT-proBNP, 33,250 (17,500-41,200) ng/L, and although median pre-dialysis $\mathrm{OH}$ decreased from 3.8 to $2.9 \mathrm{~L}$ $(P=0.047)$ NT-proBNP was not affected.

\section{Group C - symptoms of fluid depletion or absence of} symptoms but positive $\mathrm{OH}$

In group $\mathrm{C}(n=15), \mathrm{OH}$ post was $1.10(0.2-1.4) \mathrm{L}$ at baseline. The vast majority (12 out of 15 individuals) had no symptoms of either fluid overload or fluid depletion. The target weights increased in six cases, decreased in six, and were unchanged in three. At the end of the study, five individuals had reached the target for group $C$, that is $\mathrm{OH}$ post $0-2 \mathrm{~kg}$. Group $C$ had the lowest median NT-proBNP, 4050 (2160-10,650) ng/L, and NT-proBNP did not change on a group level.

\section{Group D - symptoms of fluid depletion or absence of} symptoms and negative $\mathrm{OH}$

In group $D(n=20)$, nine participants had symptoms of fluid depletion. Eleven participants reported no symptoms. At 


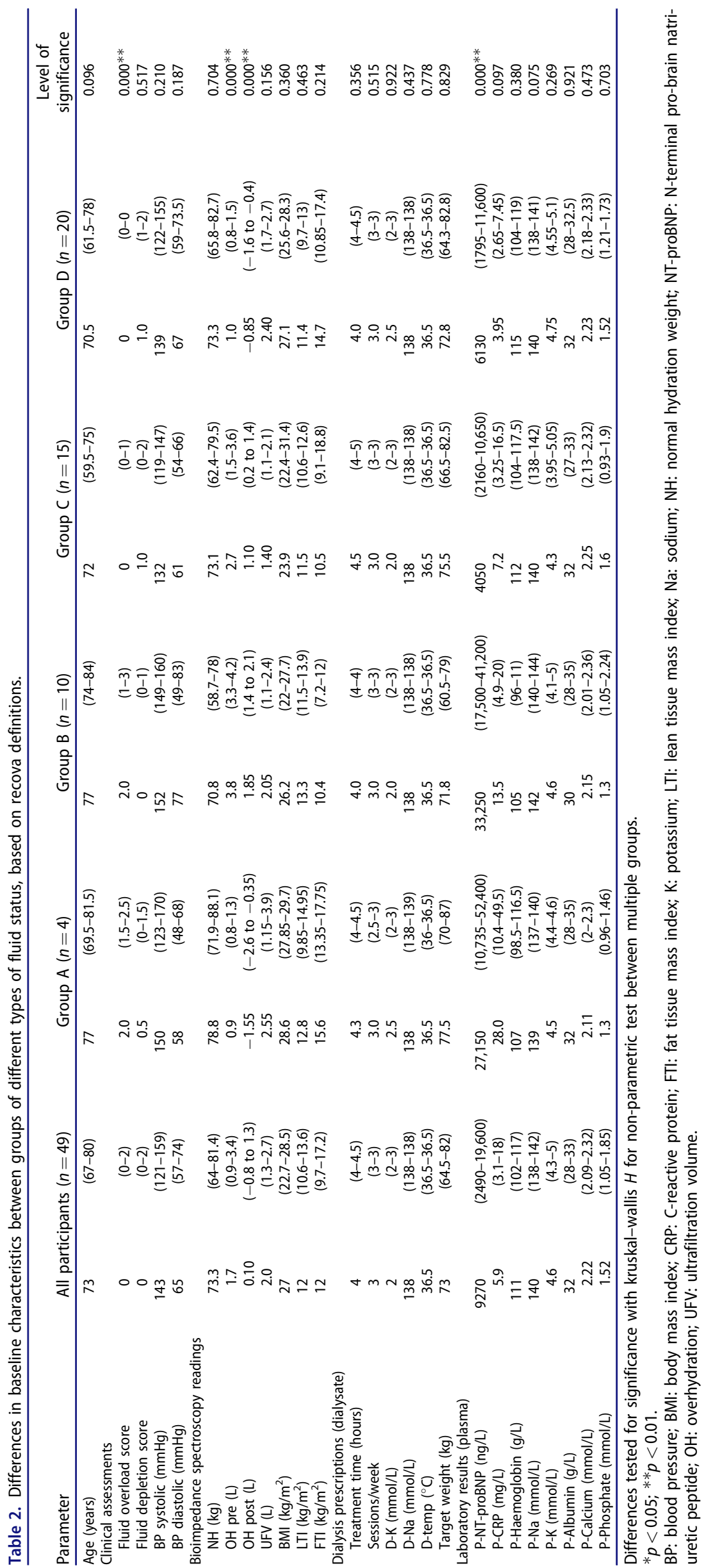


Table 3. Baseline characteristics of all enrolled patients.

\begin{tabular}{|c|c|c|c|c|c|c|c|c|c|c|c|}
\hline \multirow{2}{*}{$\frac{\text { Parameter }}{\text { Total number }}$} & \multicolumn{2}{|c|}{ All participants } & \multicolumn{2}{|c|}{ Group A } & \multicolumn{2}{|c|}{ Group B } & \multicolumn{2}{|c|}{ Group C } & \multicolumn{2}{|c|}{ Group D } & \multirow[t]{2}{*}{ Level of sign. } \\
\hline & 49 & & 4 & & 10 & & 15 & & 20 & & \\
\hline Men & 32 & (65) & 3 & (75) & 5 & (50) & 12 & (80) & 12 & (60) & 0.411 \\
\hline IHD & 18 & (37) & 2 & (50) & 6 & (60) & 6 & (40) & 4 & (20) & 0.164 \\
\hline $\mathrm{CHF}$ & 23 & (47) & 2 & (50) & 2 & (50) & 6 & (40) & 10 & (50) & 0.937 \\
\hline Stroke/TIA & 10 & (20) & 3 & (75) & 2 & (20) & 2 & (13) & 3 & (15) & $0.043^{*}$ \\
\hline PVD & 10 & (20) & 2 & $(50)$ & 1 & (10) & 3 & (20) & 4 & (20) & 0.419 \\
\hline Hypertension & 46 & (94) & 4 & $(100)$ & 8 & (80) & 15 & $(100)$ & 19 & (95) & 0.201 \\
\hline DM type 1 & 4 & (8) & 0 & & 0 & & 2 & (13) & 2 & (10) & 0.600 \\
\hline DM type 2 & 16 & (33) & 2 & $(50)$ & 10 & $(40)$ & 6 & (40) & 4 & (20) & 0.455 \\
\hline \multicolumn{5}{|c|}{ Total symptom score, thresholds and trigger } & & & & & & & 0.167 \\
\hline Level 0 points & 16 & (33) & 0 & & 0 & & 7 & (46) & 9 & (45) & \\
\hline Level $1-4$ points & 24 & (49) & 3 & (75) & 7 & (70) & 6 & (40) & 8 & (40) & \\
\hline Level $5-6$ points & 8 & (16) & 1 & (25) & 3 & (30) & 1 & (7) & 3 & (15) & \\
\hline Level $\geq 7$ points & 1 & $(2)$ & 0 & & 0 & & 1 & (7) & 0 & & \\
\hline
\end{tabular}

Differences tested for significance with the chi-square test.

Data presented as numbers of participants (\%).

$* p<0.05 ; * * p<0.01$

IHD: ischaemic heart disease; CHF: congestive heart failure; DM: diabetes mellitus; PVD: peripheral vascular disease; TIA: transient ischaemic attack.

Table 4. Measure of process.

\begin{tabular}{lccccc}
\hline Parameter & \multicolumn{2}{c}{ Baseline } & & Follow-up & Level of significance \\
\hline Haemodialysis unit 1 $(n=27)$ & & & & & \\
$\quad$ BIS/month & 0.50 & $(0.50-0.67)$ & 0.75 & $(0.75-1.0)$ & $0.035^{*}$ \\
TW adjustments/month & 0.50 & $(0.33-0.83)$ & 0.75 & $(0.50-1.25)$ & \\
Haemodialysis unit 2 $(n=22)$ & & & & & \\
BIS/month & 0.50 & $(0.50-0.67)$ & 1.00 & $(0.67-1.0)$ & $0.021^{*}$ \\
TW adjustments/month & 0.67 & $(0.33-0.83)$ & 1.00 & $(0.33-1.33)$ & $0.005^{* *}$ \\
\hline
\end{tabular}

Significance of differences between baseline and follow-up tested with wilcoxon's non-parametric test between dependent groups. $* p<0.05 ; * * p<0.01$.

BIS: bioimpedance spectroscopy; TW: target weight.

Table 5. Correlations in entire sample.

\begin{tabular}{|c|c|c|c|c|c|c|}
\hline & FD score & $\mathrm{OH}$ pre & $\mathrm{OH}$ post & NT-proBNP & BIS/month & TW changes/month \\
\hline FO score & 0.24 & 0.17 & $0.29 *$ & $0.36^{*}$ & 0.24 & 0.22 \\
\hline FD score & & -0.15 & -0.08 & -0.19 & 0.15 & 0.20 \\
\hline $\mathrm{OH}$ pre $(\mathrm{L})$ & & & $0.76^{* *}$ & $0.36^{*}$ & -0.01 & -0.03 \\
\hline $\mathrm{OH}$ post $(\mathrm{L})$ & & & & 0.21 & -0.05 & -0.05 \\
\hline NT-proBNP (ng/L) & & & & & 0.20 & 0.09 \\
\hline BIS/month & & & & & & $0.63^{* *}$ \\
\hline
\end{tabular}

$* p<0.05 ; * *<0.01$.

BIS: bioimpedance; FD: fluid depletion; FO: fluid overload; NT-proBNP: N-terminal pro-brain natriuretic peptide; OH: overhydration; TW: target weight.

baseline, $\mathrm{OH}$ post was $-0.85(-1.6$ to -0.4$) \mathrm{L}$. At the end of the study, the target weight had increased in 13 cases. The target for group $\mathrm{D}$, that is $\mathrm{OH}$ post $\pm 1.1 \mathrm{~L}$, was reached in 15 cases. When the target weight increased from 72.8 to $73.4 \mathrm{~kg}$ $(P=0.024), \mathrm{OH}$ post increased to $-0.5(-1.0$ to 0.5$) \mathrm{L}$. At the end of the study, NT-proBNP had increased from 6130 to $9625 \mathrm{ng} / \mathrm{L}(P=0.033)$.

\section{Contextual elements that interacted with the intervention}

At the first haemodialysis unit, the intervention ran for 4 months, May-August 2019. This coincided with summer holidays and staff vacations, which probably affected adherence to the study protocol and, hence, process measures.

In both haemodialysis units, changes in participants' body composition were found to interact with outcome measures. Due to changes in adipose and lean tissue mass, the target weight, as estimated at baseline, was not always adequate at the end of the study. For example, the suggested clinical response according to Recova is to either decrease (groups $A$ and $B$ ) or increase (groups $C$ and $D$ ) the target weight in order to bring relief from symptoms (Table 1). However, in group A, the target weight decreased in one participant only. Still, all four participants reached the target, $\mathrm{OH}$ post below $\mathrm{OL}$, and two out of four individuals no longer had symptoms of fluid overload. This was due to an increase in lean and adipose tissue. Conversely, in one case in group D, although the staff members adhered to the intervention and increased the target weight from 83.5 to $87.5 \mathrm{~kg}$, the participant had symptoms of fluid depletion and a negative $\mathrm{OH}$ post because of an increase in lean and adipose tissue corresponding to $4.9 \mathrm{~kg}$. A third example is in group C; due to severe decline in body weight, one participant developed symptoms of fluid overload despite a $10 \mathrm{~kg}$ target weight reduction.

\section{Details about missing data}

End-of-study data on fluid symptoms were missing in five cases. At baseline, two of these participants had reported 


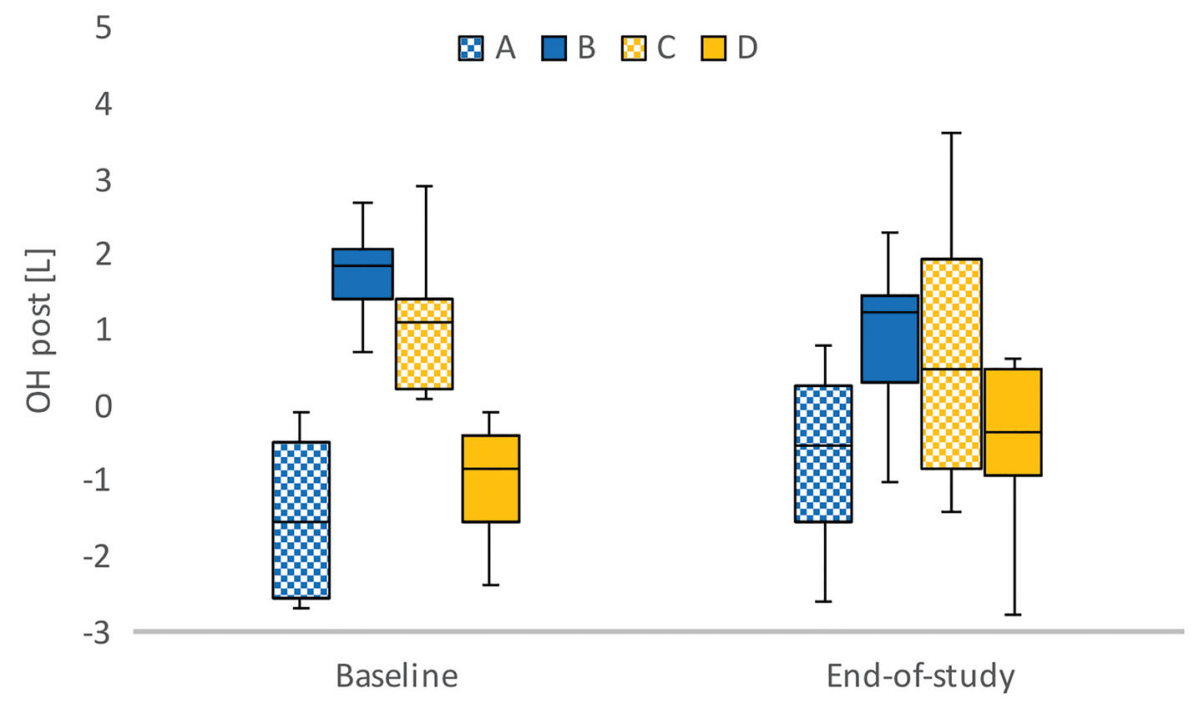

Figure 2. Bioimpedance-measured median overhydration $(\mathrm{OH})$ post in the four groups at baseline and at end-of-study.

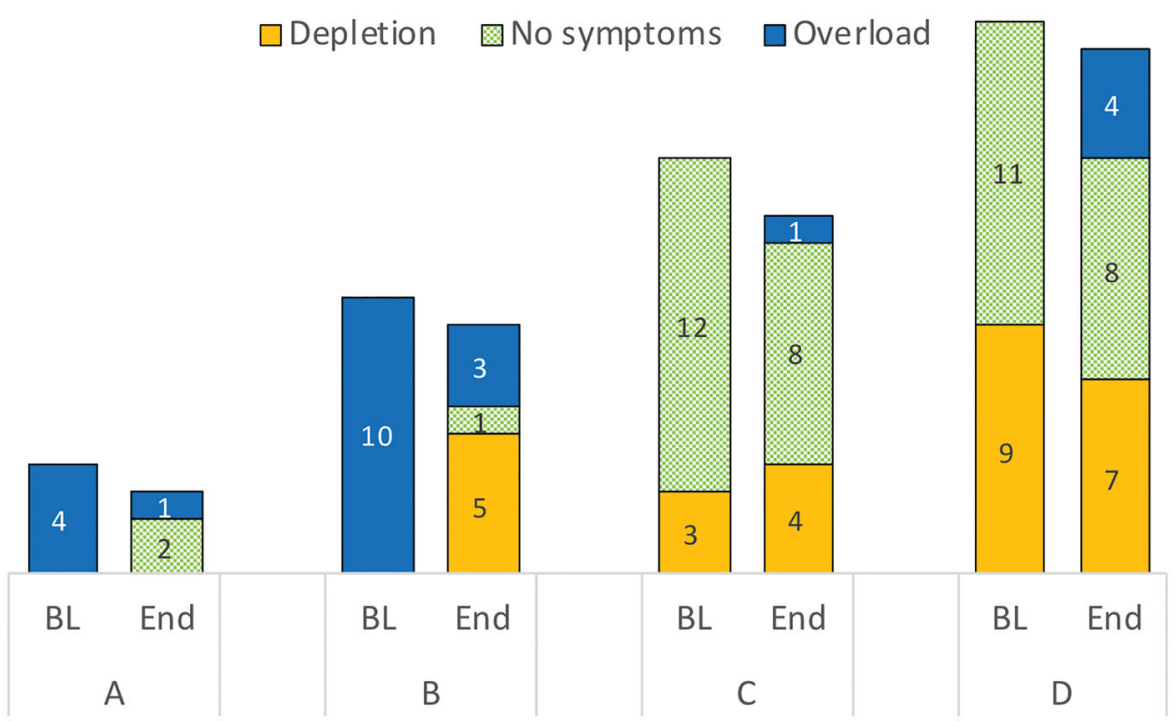

Figure 3. Comparison of distribution of pre-dialysis fluid symptom status in each group (frequencies), at baseline (BL) and at end-of-study (End).

fluid overload, whereas three had reported absence of symptoms. All five were from the first haemodialysis unit.

\section{Discussion}

This prospective intervention study evaluated the effect of a decision aid for recognition and correction of volume alterations in haemodialysis patients, the Recova tool, which combines clinical assessment and bioimpedance in target weight determination. One of the most important findings of the study is the discordance between clinically assessed fluid status and hydration status as measured using bioimpedance. Out of 49 enrolled haemodialysis patients, from two haemodialysis units, $18 \%(n=9)$ were found to have symptoms indicating an urgent need for target weight adjustment.

Based on the participants' clinically assessed symptoms and their hydration status as measured using bioimpedance, four fluid status groups ( $, B, C$, and D) were distinguished, and, by the end of the study, the frequencies of bioimpedance measurements and target weight adjustments had increased. A majority of the participants with both fluid overload symptoms and positive $\mathrm{OH}$ (group B), had decreased target weight, fewer symptoms, and decreased pre-dialysis $\mathrm{OH}$. In the group of participants with symptoms of fluid depletion and negative $\mathrm{OH}$ post (group D), the target weight had increased in 13 out of 20 participants. In the two groups in which clinical assessments and bioimpedance measurements were in conflict (group A and group C), the intervention had no effect at a group level.

Only four study participants were in group A, corresponding to symptoms of fluid overload but negative $\mathrm{OH}$ post. According to Recova, the appropriate clinical response to this group would be a decrease of target weight for symptom reduction, despite negative $\mathrm{OH}$ post. However, the target weight did not change significantly. Conversely, median $\mathrm{OH}$ post increased, and our results indicate that staff were guided more by the bioimpedance device, trying to get to $\mathrm{OH}$ post $=0$ in all cases, than by the protocol. However, the 
Table 6. Differences between baseline and follow-up observations in subgroups, significance tested with Wilcoxon's non-parametric test between dependent groups.

\begin{tabular}{|c|c|c|c|c|c|}
\hline \multirow{2}{*}{$\begin{array}{l}\text { Parameter } \\
\text { Groun A. Fluid overload sv }\end{array}$} & \multicolumn{2}{|c|}{ Baseline } & \multicolumn{2}{|c|}{ End-of-study } & \multirow{2}{*}{ Significance } \\
\hline & but neg & $-(n=4)$ & & & \\
\hline Fluid overload score & 2 & $(1.5-2.5)$ & 0 & $(0-0.5)$ & 0.102 \\
\hline Fluid depletion score & 0.5 & $(0-1.5)$ & 0 & $(0-0)$ & 0.317 \\
\hline $\mathrm{OH}$ pre $(\mathrm{L})$ & 0.9 & $(0.8-1.3)$ & 1.45 & $(0.85-2.1)$ & 0.144 \\
\hline $\mathrm{OH}$ post $(\mathrm{L})$ & -1.55 & $(-2.6$ to -0.35$)$ & -0.70 & $(-1.9$ to -0.15$)$ & 0.715 \\
\hline NT-proBNP (ng/L) & 27,150 & $(10,735-52,400)$ & 30,950 & $(9851-54,650)$ & 0.715 \\
\hline BP systolic (mmHg) & 150 & $(123-170)$ & 166 & $(131-194)$ & 0.068 \\
\hline BP diastolic (mmHg) & 58 & $(48-68)$ & 60 & $(55-76)$ & 0.144 \\
\hline Target weight $(\mathrm{kg})$ & 77.5 & $(70-87)$ & 77.5 & $(72.8-87.5)$ & 0.197 \\
\hline UFV (L) & 2.55 & $(1.2-3.9)$ & 2.70 & $(1.6-3.5)$ & 1.000 \\
\hline BIS/month & 0.42 & $(0.33-0.67)$ & 0.75 & $(0.75-0.88)$ & 0.141 \\
\hline DW adjustments/month & 0.67 & $(0.25-0.92)$ & 0.88 & $(0.50-1.38)$ & 0.197 \\
\hline \multicolumn{6}{|c|}{ Group B: Fluid overload symptoms and positive $\mathrm{OH}(n=10)$} \\
\hline Fluid overload score & 2 & $(1-3)$ & 0 & $(0-1)$ & $0.033^{*}$ \\
\hline Fluid depletion score & 0 & $(0-1)$ & 0 & $(0-1)$ & 0.129 \\
\hline $\mathrm{OH}$ pre $(\mathrm{L})$ & 3.8 & $(3.2-4.2)$ & 2.9 & $(2.6-3.4)$ & $0.047^{*}$ \\
\hline $\mathrm{OH}$ post $(\mathrm{L})$ & 1.85 & $(1.4-2.1)$ & 1.25 & $(0.3-1.5)$ & 0.074 \\
\hline NT-proBNP (ng/L) & 33,250 & $(17,500-41,200)$ & 30,150 & $(22,700-57,700)$ & 0.953 \\
\hline BP systolic (mmHg) & 152 & $(149-160)$ & 156 & $(126-172)$ & 0.959 \\
\hline BP diastolic (mmHg) & 77 & $(49-83)$ & 71 & $(48-75)$ & 0.314 \\
\hline Target weight (kg) & 71.8 & $(60.5-79)$ & 70.3 & $(56.5-79)$ & 0.067 \\
\hline UFV (L) & 2.05 & $(1.1-2.4)$ & 1.85 & $(1.3-3.1)$ & 0.919 \\
\hline BIS/month & 0.67 & $(0.42-0.75)$ & 1.0 & $(0.75-1.0)$ & 0.176 \\
\hline DW adjustments/month & 0.67 & $(0.50-0.75)$ & 1.0 & $(0.63-1.33)$ & 0.400 \\
\hline \multicolumn{6}{|c|}{ Group C: Fluid depletion or no symptoms but positive $\mathrm{OH}(n=15)$} \\
\hline Fluid overload score & 0 & $(0-1.0)$ & 0 & $(0-1.0)$ & 0.931 \\
\hline Fluid depletion score & 1 & $(0-2.0)$ & 1 & $(0-2.0)$ & 0.526 \\
\hline $\mathrm{OH}$ pre $(\mathrm{L})$ & 2.7 & $(1.5-3.6)$ & 2.7 & $(1.6-4.5)$ & 0.826 \\
\hline $\mathrm{OH}$ post $(\mathrm{L})$ & 1.10 & $(0.2$ to 1.4$)$ & 1.20 & $(-0.9$ to 2.7$)$ & 0.410 \\
\hline NT-proBNP (ng/L) & 4050 & $(2160-10,650)$ & 3320 & $(2430-9820)$ & 0.256 \\
\hline BP systolic (mmHg) & 132 & $(119-147)$ & 130 & $(122-152)$ & 0.513 \\
\hline BP diastolic (mmHg) & 61 & $(54-66)$ & 60 & $(56-69)$ & 0.132 \\
\hline Target weight $(\mathrm{kg})$ & 75.5 & $(66.8-82.5)$ & 75.5 & $(66.5-82.3)$ & 0.503 \\
\hline UFV (L) & 1.4 & $(1.1-2.1)$ & 2.1 & $(1.3-2.4)$ & 0.140 \\
\hline BIS/month & 0.5 & $(0.33-0.50)$ & 0.67 & $(0.50-1.0)$ & $0.005^{* *}$ \\
\hline DW adjustments/month & 0.5 & $(0.17-0.67)$ & 0.5 & $(0.25-1.17)$ & $0.049^{*}$ \\
\hline \multicolumn{6}{|c|}{ Group D: Fluid depletion or no symptoms and negative $\mathrm{OH}(n=20)$} \\
\hline Fluid overload score & 0 & $(0-0)$ & 0 & $(0-1.5)$ & 0.135 \\
\hline Fluid depletion score & 1 & $(0-3)$ & 1 & $(0-2)$ & 0.340 \\
\hline $\mathrm{OH}$ pre $(\mathrm{L})$ & 1.0 & $(0.8-1.5)$ & 1.3 & $(0.7-2.1)$ & 0.248 \\
\hline $\mathrm{OH}$ post $(\mathrm{L})$ & -0.85 & $(-1.6$ to -0.4$)$ & -0.5 & $(-1.0$ to 0.1$)$ & 0.057 \\
\hline NT-proBNP (ng/L) & 6130 & $(1795-11,600)$ & 9625 & $(2070-21,700)$ & $0.033^{*}$ \\
\hline BP systolic (mmHg) & 139 & $(122-155)$ & 151 & $(123-165)$ & 0.057 \\
\hline BP diastolic $(\mathrm{mmHg})$ & 67 & $(59-74)$ & 68 & $(58-74)$ & 0.852 \\
\hline Target weight $(\mathrm{kg})$ & 72.8 & $64.3-82.8)$ & 73.4 & $(66-84.5)$ & $0.024 *$ \\
\hline UFV (L) & 2.4 & $(1.7-2.7)$ & 1.9 & $(1.45-2.9)$ & 0.313 \\
\hline BIS/month & 0.67 & $(0.5-0.75)$ & 0.75 & $(0.71-1.0)$ & 0.064 \\
\hline DW adjustments/month & 0.5 & $(0.33-0.83)$ & 0.75 & $(0.59-1.33)$ & $0.005^{* *}$ \\
\hline
\end{tabular}

${ }^{*} p<0.05 ;{ }^{* *} p<0.01$.

BIS: bioimpedance spectroscopy; BP: blood pressure; FO: fluid overload; NT-proBNP: N-terminal pro-brain natriuretic peptide; $\mathrm{OH}$ overhydration; UFV: ultrafiltration volume.

low number of participants in the group prevents generalizability, and moreover the increase in target weight may be due to contextual elements affecting the outcome, that is individuals' increase in lean and adipose tissue. Nevertheless, because our results could be interpreted as indicating that staff members needed more training to gain deeper understanding of the relevant applications of bioimpedance, we want to stress the importance of individualized fluid management in haemodialysis. Since fluid depletion post-dialysis is associated with a survival benefit (23), a target weight of $1-2 \mathrm{~kg}$ below normohydration weight may be appropriate in some subjects.

Group B, with symptoms of fluid overload and positive $\mathrm{OH}$ post, had the highest NT-proBNP. Interestingly, both group A and group B - with participants reporting fluid overload symptoms - had significantly higher NT-proBNP than groups $C$ and $D$. This is despite group $A$ having negative $\mathrm{OH}$ post and group $\mathrm{B}$ having positive $\mathrm{OH}$ post. This finding underlines the importance of combining bioimpedance with other measures of fluid status for individualized target weight determination $(12,13)$. In group $B$, the target weight had decreased by the end of the study, as recommended by Recova. As high $\mathrm{OH}$ in combination with high NT-proBNP is associated with increased mortality (24), the improved hydration status in group B may be one of the most important effects of this implementation intervention. When pre-dialytic $\mathrm{OH}$ decreased, the number of participants reporting symptoms of fluid depletion also increased. Intra- and post-dialytic complications can make fluid removal difficult even in patients with significant fluid overload (25). However, symptoms of fluid depletion, as reported in group B after the intervention, may be related to the use of anti-hypertensive 
medication and to dialysis prescription rather than fluid depletion per se (26). For patients to achieve an adequate target weight, without experiencing increased intradialytic fluid depletion symptoms, a different dialysis schedule - for example more frequent or longer dialysis sessions - may be required.

According to Recova, individuals with positive $\mathrm{OH}$ but symptoms of fluid depletion, group $C$, may benefit from a target weight $1-2 \mathrm{~kg}$ above normohydration. Correction to a bioimpedance measured $\mathrm{OH}=0$ may cause hypotension if the observed $\mathrm{OH}$ is in combination with malnutrition, inflammation, low BMI, high age, and/or malignancy. There is no evidence that attaining euvolemia is feasible or desirable under these circumstances (27-29). However, in our study sample, participants in group $C$ did not have lower albumin, higher CRP, lower BMI, or higher age than participants in the other groups (Table 2). Still, the relatively low NT-proBNP (significant) and blood pressure (non-significant) confirm that individuals in group C may tolerate an increased target weight despite positive $\mathrm{OH}$. On the other hand, the vast majority of individuals in group $C$ had no symptoms of either fluid overload or fluid depletion (Figure 3). The observed absence of significant difference in target weight at the end of the study may thus be clinically appropriate.

In our study sample, a large proportion of individuals presented symptoms of fluid depletion and negative $\mathrm{OH}$ post, group D. In a recent trial, normalization of volume status in patients with negative $\mathrm{OH}$ resulted in a significant reduction in intradialytic hypotension (30). In our study, the target weight increased in this group, as recommended by Recova, and there was a small decrease in the number of individuals with fluid depletion symptoms. However, NT-proBNP also increased, with $50 \%$. This parameter was not investigated in the study by Patel et al. (30). The increase in NT-proBNP after target weight increase raises some concern, as elevated NTproBNP is associated with increased mortality in haemodialysis patients (18). However, the use of NT-proBNP as a marker of fluid overload in haemodialysis is controversial (31). The vast majority of haemodialysis patients have elevated NTproBNP levels as the peptide is renally excreted. In addition, a large proportion of the study participants had ischaemic heart disease and/or congestive heart failure (Table 3). It has been argued that serial NT-proBNP levels need to be doubled or halved in haemodialysis patients to confidently exclude changes due to analytical and biological variation alone (32).

Four individuals in group D reported symptoms of fluid overload at the end of the study. One of these individuals had reported muscle cramps as the only clinical symptom at baseline but reported a sudden increase in fluid overload symptoms between the eighth and the ninth (last) assessment, from 1 to 8 points in 3 weeks. In this case NT-proBNP also increased from $6700 \mathrm{ng} / \mathrm{L}$ to above $70,000 \mathrm{ng} / \mathrm{L}$ at the end of study. This remarkable increase probably made a substantial contribution to the increased NT-proBNP level in group D.

Accurate assessment of fluid volume status remains a concern in haemodialysis. Clinical assessment of fluid status may be imprecise and subjective (3), and there is still no consensus on which target to aim for in maintenance haemodialysis patients (29). Our results also suggest an individual's fluid status may change rapidly. Bioimpedance technology may add valuable information to this complex decision-making process. However, under certain conditions there may be a discrepancy between bioimpedance measurements and clinical assessment. Hence, bioimpedance should not be used in isolation, but in combination with clinical assessment (12). Recova defines four different types of fluid status groups and provides an overview of patients' related conditions that should be taken into consideration when using bioimpedance in target weight determination. It also systematizes the process of clinical fluid status assessment (17). The purpose of the decision aid is to facilitate interprofessional communication by defining when and how the target weight should be evaluated.

\section{Limitations}

This interventional study has several limitations. Firstly, the study is based on a relatively small sample, and the participants were not evenly distributed when divided into groups. This affects the precision and accuracy of our interpretations and hence decreases the generalizability of our findings. Moreover, we realize that the results of the intervention could have been made clearer if a 'normal' group had been identified at baseline - that is, participants without symptoms and bioimpedance-measured hydration status within the normal range, $-1.1 \mathrm{~L}$ to $+1.1 \mathrm{~L}$, who were now included in groups $C$ and $D$ (Table 1 ) although not requiring a target weight adjustment.

In order to prevent symptoms of fluid depletion when the target weight is decreased, it is usually necessary to gradually and continuously adjust blood pressure medication, alter dialysis prescriptions, and provide dietary counselling on sodium reduction. In Recova, it is suggested that target weight reduction should not be reinforced rapidly (17). However, in this study these measures were not taken into consideration, but in further research, evaluating the Recova tool, we recommend they are. Also, Recova emphasizes the need for preservation of residual renal function, but this was not routinely measured at the clinic where the trial was conducted. The nurses were encouraged to discuss residual renal function with the study participants, but this parameter could not be included in the analysis. To compensate for this limitation, all patients with residual renal function large enough to negate the need for ultrafiltration were excluded from the study.

One strength of Recova is the potential for a multidisciplinary approach. However, this implementation intervention primarily addressed nurses. The physicians at the clinic received only brief information about the tool. It is possible that a multi-professional approach could have improved adherence to protocol and the effect of the implementation. The implementation intervention was introduced similarly in two haemodialysis units, but in the first unit only $67 \%$ of the expected assessments were performed. In the second unit, 
the intervention was more closely monitored, and $100 \%$ of the expected assessments were performed, and there was a greater increase in frequencies of bioimpedance measurements and target weight adjustments. This highlights both the importance of having well-established routines for target weight assessments (15) and the need for tailored implementation strategies.

\section{Conclusions}

This prospective intervention study evaluated the effect of implementing a decision aid, Recova, in haemodialysis care. After the implementation, the monthly frequencies of bioimpedance measurements and target weight adjustments increased, and individuals with fluid overload symptoms and positive $\mathrm{OH}$ post improved in symptoms and hydration status. Study participants with symptoms of fluid depletion and negative $\mathrm{OH}$ had increased target weights, as proposed. Using Recova in guiding fluid management in haemodialysis may be beneficial. However, monitoring and adherence seem essential. This study is based on a small sample, and further studies are required to confirm the generalizability of our findings and the effect on patient outcome.

\section{Disclosure statement}

The authors report no conflicts of interest.

\section{Funding}

This study was partially funded by grants from the CUWX Counties Renal Patients' Foundation, and the Uppsala County Council. The funding sources were not involved in the study design, the collection, analysis, and interpretation of data, the writing process, or the decision to submit the article for publication.

\section{Notes on contributors}

Jenny Stenberg is a registered nurse, who obtained a PhD in Medical Sciences in 2020 at the Department of Medical Sciences, Uppsala University. She is employed at the Renal Medicine Department at the University Hospital of Uppsala and is specialized in haemodialysis.

Magnus Lindberg is a registered nurse who has worked in renal care for 25 years, mostly within the haemodialysis setting. Currently he is an Associate Professor in Caring Sciences at University of Gävle, Faculty of Health and Occupational Studies, Sweden.

Hans Furuland is a medical doctor and has a $\mathrm{PhD}$ in nephrology at the Department of Medical sciences, Uppsala University. He has been a practising clinical nephrologist for almost 30 years at the Renal Unit, Uppsala University, serving as the head of the unit for 10 of those years. He practizes in all fields of nephrology, with special emphasis on dialysis. Research interests lies within haemodialysis, diabetic nephropathy, hyperkalaemia, anaemia, and chronic inflammation.

\section{ORCID}

Jenny Stenberg (D) http://orcid.org/0000-0003-2408-0087 Magnus Lindberg (D) http://orcid.org/0000-0003-1289-9896 Hans Furuland (D) http://orcid.org/0000-0002-9001-614X

\section{References}

1. Weiner DE, Brunelli SM, Hunt A, Schiller B, Glassock R, Maddux $\mathrm{FW}$, et al. Improving clinical outcomes among hemodialysis patients: a proposal for a "volume first" approach from the chief medical officers of US dialysis providers. Am J Kidney Dis. 2014;64: 685-95. doi:10.1053/j.ajkd.2014.07.003

2. Sinha $A D$, Agarwal R. Setting the dry weight and its cardiovascular implications. Semin Dial. 2017;30:481-8. doi:10.1111/sdi.12624

3. Steinwandel U, Gibson N, Towell-Barnard A, Parsons R, Rippey J, Rosman J. Does the intravascular volume status in haemodialysis patients measured by inferior vena cava ultrasound correlate with bioimpedance spectroscopy? J Clin Nurs. 2019;28:2135-46. doi:10. $1111 /$ jocn. 14804

4. Scotland G, Cruickshank M, Jacobsen E, Cooper D, Fraser C, Shimonovich $M$, et al. Multiple-frequency bioimpedance devices for fluid management in people with chronic kidney disease receiving dialysis: a systematic review and economic evaluation. Health Technol Assess. 2018;22:1-138. doi:10.3310/hta22010

5. Wabel P, Chamney P, MoissI U, Jirka T. Importance of whole-body bioimpedance spectroscopy for the management of fluid balance. Blood Purif. 2009;27:75-80. doi:10.1159/000167013

6. Hur E, Usta M, Toz H, Asci G, Wabel P, Kahvecioglu S, et al. Effect of fluid management guided by bioimpedance spectroscopy on cardiovascular parameters in hemodialysis patients: a randomized controlled trial. Am J Kidney Dis. 2013;61:957-65. doi:10.1053/j. ajkd.2012.12.017

7. Onofriescu M, Hogas S, Voroneanu L, Apetrii M, Nistor I, Kanbay $M$, et al. Bioimpedance-guided fluid management in maintenance hemodialysis: a pilot randomized controlled trial. Am J Kidney Dis. 2014;64:111-8. doi:10.1053/j.ajkd.2014.01.420

8. Ok E, Levin NW, Asci G, Chazot C, Toz H, Ozkahya M. Interplay of volume, blood pressure, organ ischemia, residual renal function, and diet: certainties and uncertainties with dialytic management. Semin Dial. 2017;30:420-9. doi:10.1111/sdi.12612

9. Reeves PB, Mc Causland FR. Mechanisms, clinical implications, and treatment of intradialytic hypotension. Clin J Am Soc Nephrol. 2018;13:1297-303. doi:10.2215/CJN.12141017

10. Covic A, Ciumanghel A-I, Siriopol D, Kanbay M, Dumea R, Gavrilovici C, et al. Value of bioimpedance analysis estimated "dry weight" in maintenance dialysis patients: a systematic review and meta-analysis. Int Urol Nephrol. 2017;49:2231-45. doi:10.1007/ s11255-017-1698-4

11. Beaubien-Souligny W, Kontar L, Blum D, Bouchard J, Denault AY, Wald R. Meta-analysis of randomized controlled trials using toolassisted target weight adjustments in chronic dialysis patients. Kidney Int Rep. 2019;4:1426-34. doi:10.1016/j.ekir.2019.07.003

12. Tabinor M, Davies SJ. The use of bioimpedance spectroscopy to guide fluid management in patients receiving dialysis. Curr Opin Nephrol Hypertens. 2018;27:406-12. doi:10.1097/MNH. 0000000000000445

13. Dekker MJE, Kooman JP. Fluid status assessment in hemodialysis patients and the association with outcome: review of recent literature. Curr Opin Nephrol Hypertens. 2018;27:188-93. doi:10.1097/ MNH.0000000000000409

14. Stenberg J, Lindberg $M$, Furuland $\mathrm{H}$. Clinical praxis for assessment of dry weight in Sweden and Denmark: a mixed-methods study. Hemodial Int. 2016;20:111-9. doi:10.1111/hdi.12336

15. Dasgupta I, Thomas GN, Clarke J, Sitch A, Martin J, Bieber B, et al. Associations between hemodialysis facility practices to manage fluid volume and intradialytic hypotension and patient outcomes. Clin J Am Soc Nephrol. 2019;14:385-93. doi:10.2215/CJN.08240718

16. Dasgupta I, Farrington K, Davies SJ, Davenport A, Mitra S. UK national survey of practice patterns of fluid volume management in haemodialysis patients: a need for evidence. Blood Purif. 2016; 41:324-31. doi:10.1159/000444246

17. Stenberg J, Keane D, Lindberg M, Furuland H. Systematic fluid assessment in haemodialysis: development and validation of a decision aid. J Ren Care. 2020;46:52-61. doi:10.1111/jorc.12304 
18. Siriopol I, Siriopol D, Voroneanu L, Covic A. Predictive abilities of baseline measurements of fluid overload, assessed by bioimpedance spectroscopy and serum $\mathrm{N}$-terminal pro-B-type natriuretic peptide, for mortality in hemodialysis patients. Arch Med Sci. 2017;13:1121-9. doi:10.5114/aoms.2017.68993

19. Chamney PW, Wabel P, Moissl UM, Müller MJ, Bosy-Westphal A, Korth $\mathrm{O}$, et al. A whole-body model to distinguish excess fluid from the hydration of major body tissues. Am J Clin Nutr. 2007;85: 80-9. doi:10.1093/ajen/85.1.80

20. Passauer J, Petrov H, Schleser A, Leicht J, Pucalka K. Evaluation of clinical dry weight assessment in haemodialysis patients using bioimpedance spectroscopy: a cross-sectional study. Nephrol Dial Transplant. 2010;25:545-51. doi:10.1093/ndt/gfp517

21. Wabel $P$, Moissl U, Chamney $P$, Jirka $T$, Machek $P$, Ponce $P$, et al. Towards improved cardiovascular management: the necessity of combining blood pressure and fluid overload. Nephrol Dial Transplant. 2008;23:2965-71. doi:10.1093/ndt/gfn228

22. Ogrinc G, Davies L, Goodman D, Batalden P, Davidoff F, Stevens D. SQUIRE 2.0 (Standards for QUality Improvement Reporting Excellence): revised publication guidelines from a detailed consensus process. BMJ Qual Saf. 2016;25:986-92. doi:10.1136/bmjqs2015-004411

23. Dekker MJE, Marcelli D, Canaud BJ, Carioni P, Wang Y, Grassmann $A$, et al.; MONDO Initiative. Impact of fluid status and inflammation and their interaction on survival: a study in an international hemodialysis patient cohort. Kidney Int. 2017;91:1214-23. doi:10. 1016/j.kint.2016.12.008

24. Chen H, Wu B, Gong D, Liu Z. Fluid overload at start of continuous renal replacement therapy is associated with poorer clinical condition and outcome: a prospective observational study on the combined use of bioimpedance vector analysis and serum $\mathrm{N}$-terminal pro-B-type natriuretic peptide measurement. Crit Care. 2015;19:
135. doi:10.1186/s13054-015-0871-3

25. Antlanger $M$, Josten $P$, Kammer $M$, Exner I, Lorenz-Turnheim $K$, Eigner $\mathrm{M}$, et al. Blood volume-monitored regulation of ultrafiltration to decrease the dry weight in fluid-overloaded hemodialysis patients: a randomized controlled trial. BMC Nephrol. 2017;18:238. doi:10.1186/s12882-017-0639-x

26. McIntyre CW, Salerno FR. Diagnosis and treatment of intradialytic hypotension in maintenance hemodialysis patients. Clin J Am Soc Nephrol. 2018;13:486-9. doi:10.2215/CJN.11131017

27. Kim EJ, Choi MJ, Lee JH, Oh JE, Seo JW, Lee YK, et al. Extracellular fluid/intracellular fluid volume ratio as a novel risk indicator for all-cause mortality and cardiovascular disease in hemodialysis patients. PLoS One. 2017;12:e0170272. doi:10.1371/journal.pone. 0170272

28. Dekker MJE, Konings C, Canaud B, van der Sande FM, Stuard S, Raimann JG, et al. Interactions between malnutrition, inflammation, and fluid overload and their associations with survival in prevalent hemodialysis patients. J Ren Nutr. 2018;28:435-44. doi: 10.1053/j.jrn.2018.06.005

29. Ohashi $Y$, Sakai $K$, Hase $H$, Joki N. Dry weight targeting: the art and science of conventional hemodialysis. Semin Dial. 2018;31: 551-6. doi:10.1111/sdi.12721

30. Patel HV, Annigeri RA, Kowdle PC, Rao BS, Seshadri R, Balasubramanian $\mathrm{S}$, et al. Bioimpedance spectroscopy-guided ultrafiltration normalizes hydration and reduces intradialytic adverse events in hemodialysis patients. Indian J Nephrol. 2019; 29:1-7.

31. Agarwal R. B-type natriuretic peptide is not a volume marker among patients on hemodialysis. Nephrol Dial Transplant. 2013; 28:3082-9. doi:10.1093/ndt/gft054

32. Mahmood U, Johnson DW, Fahim MA. Cardiac biomarkers in dialysis. AIMS Genet. 2017;4:1-20. doi:10.3934/genet.2017.1.1 


\title{
Appendix A. The Recova ${ }^{\circledR}$ thresholds and triggers for action.
}

Based on the total score as given in the Recova symptom scoring system, see Figure 1.

2. Thresholds and triggers

\begin{tabular}{|c|c|c|}
\hline SVS Score & Response & Action \\
\hline 0 & $\begin{array}{l}\text { Evaluation of target weight (DW) } \\
\text { every second week }\end{array}$ & $\begin{array}{l}\text { Bioimpedance measurement } 2-4 \text { times/year for } \\
\text { assessment of hydration status and nutritional status }\end{array}$ \\
\hline $1-4$ & Target weight should be questioned & $\begin{array}{l}\text { Inform registered nurse, who must assess the patient, and } \\
\text { decide whether initiation of DW change is required or if } \\
\text { symptoms may be explained by other known conditions } \\
\text { (such as heart failure or advanced chronic obstructive } \\
\text { pulmonary disease). } \\
\text { Perform Bioimpedance measurement and evaluate } \\
\text { according to decision aid. Repeat measurement at three } \\
\text { occasions or until target weight is achieved. }\end{array}$ \\
\hline $\begin{array}{l}5-6 \\
\text { or } 3 \text { in a single } \\
\text { parameter }\end{array}$ & Target weight should be adjusted & $\begin{array}{l}\text { Inform clinician for assessment. } \\
\text { Perform Bioimpedance measurement without delay and } \\
\text { evaluate according to decision aid. Repeat on three } \\
\text { occasions or until achievement of target weight goal. }\end{array}$ \\
\hline 7 or more & $\begin{array}{l}\text { Immediate need for evaluation of } \\
\text { hydration status and target weight } \\
\text { adjustment }\end{array}$ & Registered nurse to immediately inform the clinician \\
\hline
\end{tabular}

\section{Appendix B. The Recova ${ }^{\circledR}$ flow chart algorithm combining clinical symptom assessment with bioimpedance spectroscopy for target weight determination}

\author{
3. RECOVA - Decision aid
}

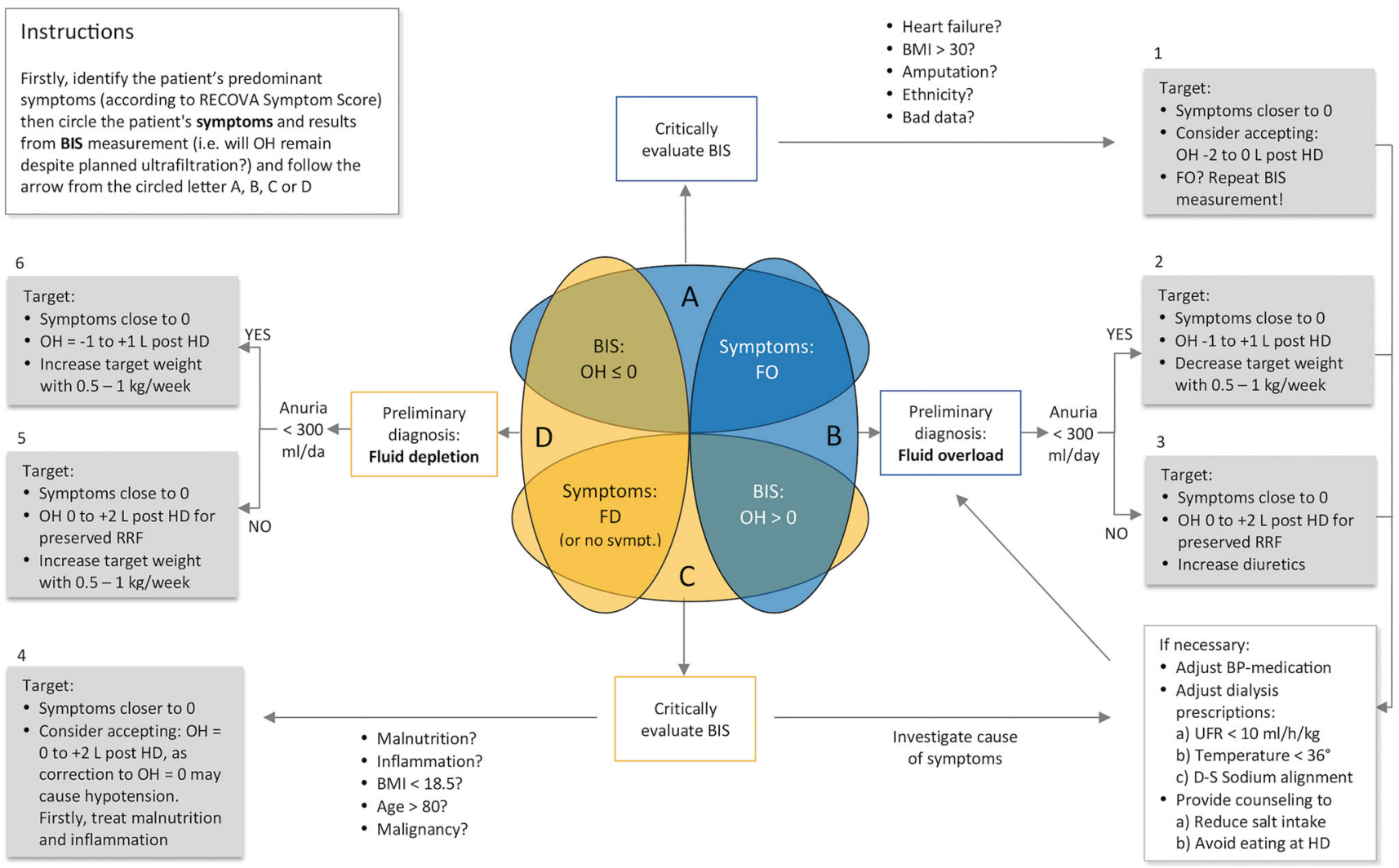

BIS: bioimpedance spectroscopy, BMI: body mass index, BP: blood pressure, D-S Sodium alignment: Prescribed dialysate sodium concentration should be equivalent to serum sodium concentration; DW: dry weight; HD: hemodialysis, FD: fluid depletion, FO: Fluid overload, OH: overhydration, RRF: residual renal function; UFR: ultrafiltration rate, UFV: ultrafiltration 